\title{
Laços desfeitos:
}

\section{análise do discurso de professoras em fim de carreira}

\section{Undone ties:}

\author{
an analysis of end-of-career teachers' speech \\ Lazos rotos: análisis del discurso de los docentes \\ de fin de carrera
}

Alessandra Müller da Silva Freitas

Universidade Estadual de Mato Grosso do Sul (UEMS), Paranaíba/MS - Brasil

Silvane Aparecida de Freitas

Universidade Estadual de Mato Grosso do Sul (UEMS), Paranaíba/MS - Brasil

\begin{abstract}
Resumo
A análise do discurso de linha francesa concebe o discurso como uma materialização da ideologia decorrente do modo de organização dos modos de produção social. Segundo essa linha de pesquisa e as concepções de sujeito de Bakhtin (2004), faremos a análise do discurso de duas professoras de língua materna em fim de carreira. O objetivo dessa análise e reflexão é depreender e problematizar as representações que as professoras fazem de si e de sua profissão. Os dados dessa pesquisa foram obtidos por meio de entrevista audiogravada e num segundo momento transcrita. Assim, concluiu-se que a identidade do sujeito pós-moderno não é fixa, mas se define historicamente, variando de acordo com as representações e interpelações culturais, o discurso das professoras é atravessado por identificações conflitantes, numa tensão constante entre um discurso que as valoriza, produto de um desejo, e outro que as desvaloriza, resultante de uma realidade social.
\end{abstract}

Palavras-chave: Discurso, Identificações, Heterogeneidade, Sujeito, Professor

\begin{abstract}
The French Analysis of Speech conceives speech as a materialization of the ideology resulting of social production organization. According to principles of the French analysis of speech and the Bakhtin's (2004) conceptions of individual, we will analyze the speech of two end-of-career Portuguese language teachers. Our aim is to reflect and analyze the image these teachers conceive of themselves and of their career as a postmodernity subject. We carried out a recorded and afterwards transcribed interview to get data for this research. Therefore, it is concluded that the identity of the individual in postmodern society is not immovable, but it is defined along history according to cultural matters, so that the teachers' speeches point out a constant tension between a speech that values them, product of a desire, and another that depreciates them, resultant of a social reality.
\end{abstract}

Keywords: Speech, Identifications, Heterogeneity, Individual, Teacher 


\section{Resumen}

El análisis del discurso de línea francesa concibe el discurso como una materialización de la ideología resultante del modo de organización de los modos de producción social. De acuerdo con esta línea de investigación y las concepciones de sujeto de Bakhtin (2004), analizaremos el análisis del discurso de dos maestros de lengua materna al final de la carrera. El propósito de ese análisis y reflexión es inferir y problematizar las representaciones que los maestros hacen de sí mismos y de su profesión. Los datos de esa investigación se obtuvieron a través de una entrevista grabada en audio y en un segundo momento transcrita. Con eso, se concluye que la identidad del sujeto posmoderno no es fija, sino que está históricamente definida, variando de acuerdo con las representaciones e interpelaciones culturales, el discurso de los maestros está atravesado por identificaciones conflictivas, en una tensión constante entre un discurso que los valora, producto de un deseo y otro que los devalúa, como resultado de una realidad social.

Palabras clave: Discurso, Identificaciones, Heterogeneidad, Sujeto, Maestro

\section{Introdução}

Considerando que a educação é o lugar por excelência dos conflitos de valor, centro de nossas angústias coletivas, Saviani (2006) ressalta que a escola disponibiliza os instrumentos pelos quais o aluno pode se organizar para romper a relação de exploração burguesia x proletariado. A ação pedagógica constitui um dos fundamentos da identidade profissional do professor (GAUTHIER, 2003), já que as escolhas feitas no plano pedagógico procedem de uma escolha política por parte do educador. Ponderemos também que, no estado de Mato Grosso do Sul, aproximadamente $35 \%$ dos professores que atuam na educação básica têm mais de 40 anos e, no país, esse número alcança $40 \%$ do total de professores ${ }^{11}$. Ainda ressaltamos que a idade mínima para aposentadoria de profissionais do sexo feminino é 50 anos de idade e do sexo masculino de 55 anos. Podemos inferir, desse modo, que essa porcentagem se refere a profissionais que estão entrando na fase de fim de carreira. Nesse sentido, propomo-nos, no presente artigo, a descrever, interpretar, problematizar e analisar os dizeres dos sujeitos-professores em fim de carreira, para entendermos as condições de produção desses discursos e as representações que esses docentes fazem de si e de sua profissão, identificando formações discursivas e ideológicas que constituem o seu discurso.

\footnotetext{
${ }^{1}$ Estudo do Professor - Tabela A2 - Comparativo da Proporção de Professores da Educação Básica por Faixa Etária, Brasil-Mato Grosso do Sul, 2007. Censo Escolar da Educação Básica 2007: Disponível em: <http://portal.mec.gov.br/plano-nacional-de-formacao-de-professores/censo-doprofessor>. Acesso em: 20 ago. 2020
} 
O educador, homem ocidental, tem a ilusão de que é coerente quanto às suas crenças, tem a ilusão de que é um sujeito único, acredita que a verdade se encontra em alguém ou em algum lugar e que é preciso lutar para atingi-la, tentando colocar em prática o que lhe é ensinado. Talvez não seja possível escapar a essa tendência teleológica, mas necessário é questioná-la, a fim de enfrentar e, por que não, transpormos essa realidade que tem se tornado um desafio para os educadores.

Nesse sentido, sob a direção dos pressupostos da análise do discurso de orientação francesa, faremos a análise do discurso de professores em final de carreira. Foram selecionados recortes de enunciados, em que se revelam as representações que os docentes fazem de si como sujeitos sócio-históricos e como essas representações se constituem e constituem a identidade desse profissional.

Servimo-nos, neste trabalho, da aplicação de entrevista para coleta do discurso dos professores, sujeitos da pesquisa, como abordagem de coleta de dados, pois nos garante maior flexibilidade para se garantir a resposta desejada, permite uma maior profundidade, estabelece uma relação de confiança e amizade entre pesquisador/pesquisado, propiciando o surgimento de outros dados, elemento precioso para a análise do discurso. As perguntas da entrevista são do tipo abertas, cuja resposta é livre, não limitada por alternativas apresentadas. O pesquisado fala ou escreve livremente sobre o tema que lhe é proposto. As perguntas do tipo aberta fornecem respostas mais profundas a respeito dos tópicos aos quais elas se relacionam, além de suscitarem análises mais complexas e mais densas (GOLDENBERG, 2009).

Este trabalho é resultado de pesquisa realizada para apresentação de monografia no curso de especialização em letras, estudos em linguagem, oferecido pela Universidade Estadual de Mato Grosso do Sul. A coleta de dados foi realizada pela própria pesquisadora, por intermédio de entrevista semiestruturada, de modo individual (primeiramente audiogravada e num segundo momento transcrita), com quatro professores efetivos do ensino fundamental, da rede pública do município de Cassilândia, Mato Grosso do Sul.

Neste artigo, selecionamos a amostra de apenas dois professores, em fase final de carreira, a qual servirá ao objetivo aqui proposto. As oito questões da entrevista (também selecionadas, devido aos limites deste trabalho) foram elaboradas, objetivando oportunizar ao docente falar sobre seu percurso como professor, suas representações acerca de si mesmo e sua profissão, a fim de que despertar a sua 
memória discursiva, momento em que ele pode expor os conflitos e contradições do discurso, alvo de nossa pesquisa.

\section{A análise do discurso e o sujeito pós-moderno}

O movimento histórico determina a formação e a desestabilização das identidades do sujeito. Foucault (apud SILVA, 2000) entende que o sujeito é resultado de um processo de produção cultural e social. Para a compreensão histórica do processo de ensino, estabelecemos as relações entre conteúdo de ensino e produto da pesquisa científica em cada época, pois, segundo Geraldi (1995, p. 95), "em função desta relação, diferentes identidades foram construindo a ação de ensinar e, consequentemente, foram definindo a identidade do professor de língua portuguesa".

Movimento intelectual surgido na segunda metade do século XVIII, o lluminismo enfatizava a razão e a ciência como formas de explicar o universo. O sujeito dessa época era concebido como um indivíduo totalmente centrado, unificado, dotado das capacidades de razão, de consciência e de ação; o homem racional e científico, conhecido como sujeito cartesiano (HALL, 2005). Até o início da modernidade, o mestre se caracterizava pelo fato de ser um produtor de conhecimento, produtor de um saber, de uma reflexão, participante de uma elite cultural. Geraldi (1995) afirma que, entre aquele que ensina e aquele que produz conhecimento, não há uma separação radical. À medida que as sociedades foram se tornando complexas, adquirindo uma forma mais coletiva e social, o antropocentrismo foi sendo questionado. O sujeito sociológico reflete essa mudança. Nascia a consciência de que o núcleo interior do sujeito não é autônomo e autossuficiente. Segundo Hall (2005), a identidade passou a ser formada na 'interação' entre o eu e a sociedade.

Geraldi (1995) ressalta que, nos séculos XIV e XV, a sociedade mercantilista, livre da ingerência da Igreja e do império, vendia sua ciência, renovava-a e revolucionava os métodos de ensino; surgiu a utopia da universalização do ensino. $\mathrm{A}$ urgência de instrução demandava a formação de instrutores; emergia então o professor. Nesse sentido, contemplamos uma divisão social do trabalho responsável pelo surgimento de uma nova identidade, na qual o mestre já não se constituía pelo saber que produzia, mas por um saber produzido que ele transmitia. O resultado do trabalho científico se transformou em conteúdo de ensino, mesmo que não respondesse a qualquer necessidade do aluno, ensinados apenas para responder à exigência do próprio sistema (GERALDI, 1995). 
A sociedade moderna, na sua ânsia de ordem e controle, buscou elaborar teorias e explicações que fossem o mais abrangentes possíveis, que reunissem num único sistema a compreensão total da estrutura e do funcionamento do universo e do mundo social. O estruturalismo de Saussure (1995) refletia esse momento da sociedade moderna. Esse autor concebia a língua como um sistema abstrato de um número limitado de regras sintáticas e gramaticais, que determina quais combinações e permutações são válidas em qualquer língua particular. A linguagem se tornava, na visão desse autor, um sistema estável e imutável de elementos.

O fenômeno da globalização e as tendências à autonomia nacional, por sua vez, implicaram num movimento de distanciamento do sujeito sociológico. As identidades nacionais começaram a se desintegrar como resultado da homogeneização cultural e das influências externas da globalização; novas identidades tomaram seu lugar. A nova configuração introduziu na relação entre a atividade de produção de conhecimentos e a atividade de ensino uma nova realidade; a produção de material didático posto à disposição do trabalho de transmissão, conferiu "concretude" ao discurso pedagógico e substituiu a reflexão pelo automatismo (ORLANDI, 1983).

O pós-modernismo chegou suscitando uma desconfiança profunda quanto às pretensões totalizantes do saber do pensamento moderno; preferia-se o subjetivismo das interpretações parciais e localizadas, inclinava-se para a incerteza e a dúvida. Inserido nessa sociedade, assim é o professor, sujeito de nossa pesquisa, um sujeito que não é uno, mas composto de várias identidades, muitas vezes, contraditórias ou não resolvidas.

Dessa forma, a análise do discurso (doravante $A D$ ) de orientação francesa, nos dará subsídios a este trabalho, pois considera a linguagem como parte constitutiva da produção de sentidos, o contexto histórico-social e ideológico. Orlandi (1999, p. 17) ressalta que não devemos considerar nem a linguagem e nem a sociedade como um produto, pois ambas se constituem mutuamente; "os processos que entram em jogo na constituição da linguagem são processos histórico-sociais." Não existe sentido em si; o sentido vai sendo determinado à medida que as posições ideológicas vão sendo colocadas em jogo. Para Althusser (apud MUSSALIN, 2004), a linguagem se coloca como uma via por meio da qual se pode depreender o funcionamento da ideologia.

Relacionando três domínios disciplinares, a linguística, marxismo e psicanálise, a AD nos fornece dispositivos teóricos para interpretação, na medida em que descreve 
os processos internos de controle do discurso que o normatizam com noções sobre formação discursiva (FOUCAULT, 2006). A linguagem, nesta perspectiva, trabalha com o fundamento dialógico da linguagem, sob o olhar da concepção do materialismo histórico e postula que, no ato da linguagem, nos filiamos a redes de sentidos e somos afetados pela ideologia e pelo inconsciente (ORLANDI, 1999). Nesse sentido, a visão bakhtiniana de dialogismo vem nos antecipar a questão da Análise do Discurso, que se opõe à visão saussuriana de linguagem; para Bakhtin (2004), a linguagem é um fenômeno social e histórico, e por isso, também ideológico.

Rompendo com o século XIX, a AD desconstrói a unidade do sujeito de direito ou sujeito jurídico da modernidade, o sujeito mestre de suas palavras, que determina o que diz, e descortina uma proposta de reflexão sobre a linguagem, sobre o sujeito, a história e a ideologia em que o exercício é interpretar, distantes, porém, da ilusão de sermos conscientes de tudo. Dessa forma, a AD considera os processos e as condições de produção da linguagem, relacionando-a à sua exterioridade. Nesse sentido, no que se refere à maneira como a linguagem está materializada na ideologia e como a ideologia se manifesta na língua, estamos sujeitos à linguagem, seus equívocos e opacidade, comprometidos com os sentidos e o político (ORLANDI, 1999).

Nesse sentido, a AD parte do pressuposto que todo funcionamento da linguagem se assenta na tensão entre processos parafrásicos e processos polissêmicos, a estabilização e o deslocamento, em que fica latente a ruptura de processos de significação. As palavras não são somente nossas, elas significam pela história e pela língua (ORLANDI, 1999). Todo dizer se encontra na confluência de dois eixos: o da memória (constituição) e o da atualidade (formulação), em uma relação constante entre o já-dito e o que se está dizendo (interdiscurso e intradiscurso). Entre a paráfrase e a polissemia, está o trabalho do analista, buscando a compreensão das interrelações entre o político e o linguístico na constituição dos sujeitos e na produção dos sentidos, ideologicamente assinalados e num espaço regido pelas representações das relações de poder.

Não se procura o sentido "verdadeiro", mas o real do sentido em sua materialidade linguística e histórica, em que os sentidos e os sujeitos se constituem em processos nos quais há transferências, jogos simbólicos dos quais não temos o controle. Soma-se a isso, o fato de que, para Foucault (2006), a verdade é produzida no acontecimento. 
Orlandi (1983) salienta que "o sujeito que produz linguagem também está reproduzido nela, acreditando ser a fonte exclusiva de seu discurso, quando, na realidade, retoma um sentido preexistente" (p. 19-20). Coracini (1997) complementa que o sujeito não é o centro da ação social; ele é pensado, falado e produzido, já que "todo dizer aponta para um outro que o constitui" (p. 40).

Segundo Foucault (2006), o discurso não é uma estreita superfície de contato, ou de confronto, entre uma realidade e uma língua. Ao analisar um discurso, vemos desfazerem-se os laços aparentemente tão fortes entre as palavras e as coisas e se destacar um conjunto de regras, próprias da prática discursiva, o que podemos chamar de formação discursiva, ou seja, aquilo que, numa formação ideológica dada, determina o que pode e deve ser dito, nos permite compreender o processo de produção dos sentidos, a sua relação com a ideologia e também nos possibilita estabelecer regularidades no funcionamento do discurso. Por sua vez, denominamos de formação ideológica o confronto de forças em um dado momento histórico, em que o sentido vai sendo determinado, à medida que as posições ideológicas vão sendo colocadas em jogo.

A interpretação aparece em dois momentos da análise: num primeiro, o sujeito, quando fala, interpreta, e o analista deve procurar descrever esse gesto de interpretação do sujeito; em segundo momento, o analista deve atravessar o efeito de transparência da linguagem, investindo no descentramento do sujeito e no efeito metafórico, no equívoco, na falha, no trabalho da ideologia, até mesmo o dizer tem relação com o não dizer, e esse fenômeno deve também estar sob análise.

Dessa forma, ao propormos analisar os discursos dos professores em fim de carreira, estaremos refazendo o trabalho da expressão, ou seja, retomando "enunciados conservados ao longo do tempo e dispersos no espaço, em direção ao segredo interior que os precedeu, neles se depositou e aí se encontra traído" (FOUCAULT, 2008, p. 137).

\section{Os desafios do ensino de língua portuguesa}

Concepções equivocadas sobre língua, linguagem e ensino de língua têm perpetuado dificuldades na educação. Problemas de ordem política, econômica e social também são contribuintes para o quadro da educação no país. Segundo Geraldi (1995), os estudos clássicos de línguas mortas deixaram herança, na medida em que 
inspiraram tanto as descrições linguísticas de línguas vivas quanto a forma de as conhecer na escola, fator que contribuiu generosamente para que o ensino de línguas nunca tivesse se inspirado na prática de linguagem. A gramática, estudo inaugurado pelos gregos, era baseada na lógica, desprovido de qualquer visão científica e desinteressada da própria língua, visava unicamente a formular regras para distinguir as formas corretas das incorretas.

Somente no início do século XVIII, a linguística se tornou uma ciência, definindo seu objeto de estudo. Saussure (1995), responsável por esse estudo, fundador da linguística moderna, priorizava o sistema linguístico sincrônico em detrimento dos fatores ligados à enunciação e à realidade social. A partir da década de 1980, os estudos na $A D$ de linha francesa, juntamente à linguística da enunciação e à sociolinguística, sob uma visão sociointeracionista de linguagem, trouxeram ao ensino de língua materna a contribuição de compreender a linguagem como uma interação verbal entre locutores socialmente situados (CARDOSO, 2005). Diante desses pressupostos, novas concepções sobre o processo ensino/aprendizagem da língua materna têm sido defendidas, desde a década de 1980, sem contudo serem apropriadas pela maioria dos professores (MARTINS, 2002).

Documento fundado em concepções teóricas recentes e inovadoras, os PCN (BRASIL, 1998) propõem uma metodologia enunciativo-discursiva, que rompe com a concepção de ensino tradicional de fundo normativo e conceitual de língua materna. A produção e compreensão de discursos deve ser o ponto de partida e a finalidade do ensino de língua, uma atividade de prática sócio-histórica viva e reflexiva. Propõemse a estabelecer diretrizes curriculares para o ensino fundamental e servir de apoio ao trabalho do professor.

Os PCN (BRASIL, 1998) ainda sugerem o estabelecimento de dois eixos para o ensino de língua: um que enfoca o uso da linguagem e outro que enfoca a reflexão sobre a língua e linguagem. O que se pretende a partir das perspectivas propostas é uma atividade permanente de formulação e verificação de hipóteses - retomando o processo de fazer ciência - sobre o funcionamento da linguagem. Esse documento ainda se preocupa com a transposição didática e coloca a importância de uma reformulação da formação inicial e contínua de professores, levando-os ao conhecimento da teoria e da prática subjacente aos PCN (BRASIL, 1998), a fim de que aconteça uma implementação real dos parâmetros no ensino (ROJO, 2000) 
Para os educadores, talvez, seja até fácil aceitar certos princípios teóricos. O difícil é fazer da prática um ato consistente e coerente com os pressupostos assumidos. Assim, acontecem contradições entre a prática e a teoria que se pretende assumir. Dessa maneira, os atuais procedimentos de ensino não têm sido suficientes para um efetivo ensino/aprendizagem nas três práticas: de leitura, produção e análise linguística. Segundo Martins (2002), é preciso que os educadores tenham um embasamento teórico mais sólido, para que possam produzir princípios, a fim de agir com mais clareza e confiança, evitando angústias com o aparente fracasso dos métodos. Na verdade, a mudança no como fazer só se torna mudança, se gerar uma mudança no porquê e para quê, ou seja, implica na produção de uma proposta de ensino, a partir de um projeto (MAGNANI, 1997).

\section{Desfazendo os laços: a análise}

Ao iniciar as análises, é essencial considerar que tanto o sujeito como os sentidos do discurso são constituídos no interior das formações discursivas. 0 discurso, ao mesmo tempo, remete à formação discursiva e é regido também por essa mesma prática (CARDOSO, 2003). As formações discursivas, por sua vez, compreendem as grandes unidades históricas que os enunciados constituem e o lugar onde se articulam discurso e ideologia.

No entanto, o sujeito, ocupando o lugar que ocupa em uma dada formação social é dominado por uma determinada formação ideológica que preestabelece as possibilidades de sentido de seu discurso, ou seja, o sujeito não é totalmente livre para dizer o que quer. Segundo Orlandi (1983), onde está a linguagem, aí também está a ideologia. Assim, abordaremos as formações discursivas de onde o sujeito enuncia, bem como as formações ideológicas em jogo.

Selecionamos as entrevistas realizadas com duas professoras, uma já aposentada, porém, ainda lecionando na rede privada de ensino do município de Cassilândia (chamaremos de $\mathrm{Aa}$ ) e a outra professora nos últimos anos de sua profissão, faltando apenas sete para se aposentar (chamaremos de F7). Ambas têm sua formação em letras, em faculdades particulares do estado de São Paulo. Somente a primeira prosseguiu os estudos em um curso de pós-graduação, nível de especialização.

A questão 1 versa sobre a opção por ministrar a disciplina língua portuguesa. A professora $(\mathrm{Aa})$ revela em seu discurso as imagens positivas tradicionais, de que 0 
professor é um missionário e já nasce com o dom para ser professor, preservando o seu papel de detentora do saber: "Porque eu sempre gostei de escrever, adoro fazer redação, sou apaixonada por literatura, nunca fiquei sem ler".

O discurso da professora (F7) revela certa objetividade, contudo, há sentidos que foram silenciados: "dentre os outros cursos, este me pareceu mais adequado". Quando ela fala em outros cursos, a que cursos ela se refere? Aos que ela escolheu? Aos que estavam acessíveis a ela? E o que significa adequado? Adequado às suas condições financeiras para manter o curso? Aos seus anseios profissionais e financeiros?

Foucault (2006) sustenta que um enunciado é sempre um acontecimento, que nem a língua nem o sentido podem esgotar inteiramente. Ela tenta manter a objetividade, embora lhe escape, por meio do não dito, um sentimento de conformismo e frustração.

Quanto ao objetivo do ensino de língua portuguesa (questão 2), destacamos o enfoque dado à leitura. A professora $(\mathrm{Aa})$ relata que "leitura é vida", uma descrição um tanto vaga. A professora (F7) diz: "(... ) mas o principal deles é fazer com que o aluno leia". Porém, em nenhum momento, vemos de que maneira se dá esse ensino de leitura. Por que e para quê ler? Geraldi (1995) afirma que a leitura forma o sujeito, afinal o sujeito se constitui no e pelo olhar do outro, segundo a visão dialógica de Bakhtin (2004).

Notamos também uma lacuna quanto à produção textual. Segundo Geraldi (1995), o ensino de língua portuguesa deve centrar-se nas atividades de leitura, produção textual e análise linguística. Pelo discurso da professora $(\mathrm{Aa})$, temos implícito o pressuposto de que se o sujeito ler e ler muito, ele vai aprender a falar e escrever corretamente, porque, primeiramente, ela fala sobre a importância da leitura, e depois, comenta sobre o erro de um professor, ou seja, se aquele professor lesse, não estaria incorrendo no erro. Diríamos que não há erro em questão de língua, mas inadequações de acordo com a situação.

Consideremos também a preocupação dessa professora $(\mathrm{Aa})$ com a imagem do sujeito-professor: "Eu acredito que um médico mata um ser humano se ele errar, e uma professora mata uma geração". Devemos considerar a enunciação como correlato de uma certa posição sócio-histórica; a professora assume o lugar que the foi conferido ao longo dos anos, de detentora do saber, uma imagem a ser preservada como maneira até mesmo de preservar sua autoridade institucional (MARTINS, 2002). 
Assim, uma formação discursiva, apesar de heterogênea, sofre as coerções da formação ideológica em que está inserida (MUSSALIN, 2004).

Observamos que a grande preocupação das novas contribuições da educação quanto à ortografia, concordância, contextualização, argumentação, língua padrão versus não padrão, parece estar bem resolvida para as professoras em fim de carreira, a maior preocupação demonstrada foi com a leitura. Segundo Huberman (1992), os professores, nesse estágio, evocam uma grande 'serenidade'.

Perguntamos sobre a concepção de língua (questão três). O discurso da professora (F7) nos revela uma abordagem comunicativa da língua e exclui o seu caráter dialógico e histórico: "Eu entendo a língua como uma das formas de comunicação que nós humanos estabelecemos. A nossa comunicação nos difere dos outros animais". A professora (Aa) fala: "Pra nós brasileiros, é nossa língua mãe", expressão que nos conduz à língua materna, língua mãe, com a qual aprendemos a falar. Em seguida, ela introduz um novo enunciado: "Desde o início, a gente já tinha que falar corretamente, mas infelizmente nem todas as camadas sociais falam". Segundo Martins (2002), ao fazermos uso desse ou daquele discurso, não estamos apenas repetindo um discurso, mas deslocando-o para outra dimensão sóciohistórica, e, por isso, novos sentidos são construídos. É o que ocorre a partir da segunda linha: em que há a presença da marca da negação por meio do prefixo in e da conjunção nem; Mussalin (2004) afirma que essa é uma forma de heterogeneidade marcada na superfície do discurso, uma das formas linguísticas que demonstram os diferentes modos de negociação do sujeito falante com a heterogeneidade constitutiva do discurso.

É por meio da forma negativa, que se apresenta a formação ideológica nesse discurso. A negação in e nem marcam um discurso que revela a marginalidade social e imprime à classe menos favorecida o fado do fracasso, ao afirmar que "(...)mas infelizmente nem todas as camadas sociais falam(...)". A contraposição dos dois destinos revela o distanciamento entre os lugares sociais ocupados por aqueles a quem a sociedade valoriza e aqueles a quem ela rejeita, "(...)porque se eu convivo no meio de pessoas que falam corretamente, a criança sai falando corretamente, agora, se a criança convive num lar onde os pais falam errado, óbvio que a criança vai falar errado".

Segundo Orlandi (1983), a escola aparece como colaboradora, que harmoniza a transmissão de um patrimônio cultural tratado como bem comum. Ela tem uma 
função de dissimular, na medida em que apresenta "hierarquias sociais e da reprodução dessas como se estivessem baseadas na hierarquia de dons, méritos ou competências e não como hierarquia fundada na afirmação brutal de relações de força" (p. 16 e 17). São convertidas hierarquias sociais em hierarquias escolares, legitimando assim a perpetuação da ordem social.

Dessa forma, a posse de bens culturais, selecionados como indispensáveis por determinada formação social, supõe a posse prévia de um código que permite decifrálos. Só prevalece aquele que tem oportunidades, só tem oportunidades aquele que prevalece, instalando-se desse modo uma circularidade. Nesse sentido, Althusser (apud MUSSALIN, 2004) afirma que a classe dominante, para manter sua dominação, gera mecanismos que perpetuam e reproduzem as condições materiais, ideológicas e políticas de exploração. Dentre esses mecanismos de reprodução, está a escola, importante aparelho ideológico do Estado.

Eckert-Hoff (2003) nos alerta para o uso das modalidades aléticas ou lógicas: "se a criança convive num lar onde os pais falam errado, óbvio que a criança vai falar errado (Aa)" (grifos meus). A modalidade lógica é óbvio que responde por um efeito de sentido de verdade, pois, pela incorporação da intersubjetividade (todos sabem disso, que a criança vai falar errado), funciona como uma espécie de argumento de autoridade, ao mesmo tempo, tem a capacidade de acuar o interlocutor, colocando-o diante da obrigação de saber a lógica do discurso.

A professora então conclui: "A escola é a única oportunidade pra esta criança". Ou seja, o que vemos implícito é que a escola é a única salvação para os problemas, de marginalidade social, inclusive, dessa criança que não sabe falar "certo". Esse é um discurso veiculado pela escola, que age/funciona como dissimuladora da reprodução social. Cremos que a escola pode, sim, oferecer uma saída, se ela e professor se comprometerem a despertar "o espírito crítico e a consciência revolucionária do aluno, para ele apoderar-se dos conteúdos de ensino como instrumentos de dominação e transformar a sociedade" (MAGNANI, 1997, p. 26). Será que nossos professores já se deram conta disso?

E qual seria, na concepção dessas professoras, a importância da gramática para o ensino da língua portuguesa? (questão quatro). Podemos notar que a professora $(\mathrm{Aa})$ defende a necessidade de se trabalhar a produção textual. "Ela (a gramática) tem que caminhar com a interpretação, com a leitura, se for falar de concordância verbal, vamos falar num texto. A melhor forma de trabalhar a gramática 
é na reestruturação de texto". Destacamos palavras como leitura, texto, reestruturação de texto, que evocam um ensino interativo da língua. No entanto, ela se contradiz, parece que ainda não se apropriou de uma teoria mais inovadora, insiste nas formas tradicionais do ensino da produção escrita, mediante a importância dada ao uso da gramática, das regras, o formalismo das nomenclaturas: "Se o aluno não sabe nomear, ele vai descobrir que tem, sim, um nome na gramática que é concordância verbal" (Aa). O texto, nesse caso, se torna apenas um pretexto (GERALDI, 1995) para o ensino da gramática. É válido lembrar que os PCN (BRASIL, 1998) criticam o ensino que trabalha com textos fechados, ou seja, com modelos preestabelecidos em aspectos e funções exclusivamente escolares, pois, desse modo, se afastam da proposta do dialogismo bakhtiniano. Ainda, segundo Coracini (1998), o professor pode assimilar teoricamente os princípios de uma determinada metodologia e, na prática, proceder de acordo com uma mistura de fragmentos teóricos, e não teorias completas e coerentes; é exatamente o que percebemos no discurso da professora ( $\mathrm{Aa}$ ).

$\mathrm{Na}$ fala da professora (F7), não ficam explícitas as contradições quanto aos métodos, objetivos e conteúdos de ensino, como observamos no discurso da professora $(\mathrm{Aa})$ : "Quando se entra num jogo, se entra sabendo parte da regra; se você não ensinar a regra, como é que ele vai saber, só vendo a palavra acentuada. A regra tá aí pra ser ensinada". A professora reafirma o seu discurso de tradição e deixa transparecer a serenidade adquirida ao longo dos anos de carreira. Segundo Hubberman (2003), as investigações psicológicas clássicas sublinham certa tendência (visto que faltam apenas sete anos para essa professora se aposentar) à maior resistência às inovações, pois, afinal, a forma como aprendeu e sempre ensinou é a única correta para ela. É certo também que todo discurso remete à formação discursiva a que pertence, sendo regido por essa prática (CARDOSO, 2003).

A questão cinco dispõe sobre as atividades que mais gostam de desenvolver em sala de aula: "A reestruturação de texto e redação"(Aa). "Eu gosto de fazer com que eles leiam, escrevam, que eles procurem pistas no texto, que são os elementos de coesão. Procuro fazer essas releituras do texto" (F7). As professoras usam expressões atuais como: reestruturação (Aa) e releitura (F7). Segundo Orlandi (1983), os discursos se sustentam mutuamente e, por isso, compartilham marcas. Porém, a formação discursiva denota o aspecto tradicional: "Adoro ensinar a narrar, dissertar, descrever" (Aa). De acordo com a autora, isso se dá, porque a formação discursiva delimita aquilo que se deve e se pode dizer em determinadas condições de produção, 
atuando como um conceito mediador, no sentido de que "é configurado por certas marcas, certos traços formais, ao mesmo tempo em que é definido por sua relação com a formação ideológica" (ORLANDI, 1983, p 207).

A professora $(\mathrm{Aa})$ reproduz o ensino consagrado pela tradição escolar; modelos que devem ser aprendidos e seguidos. Segundo Rojo (2000), esses procedimentos não têm sido suficientes para um efetivo ensino-aprendizado do domínio da escrita. Tipologias como narração, descrição e dissertação são trazidas de teorias linguísticas calcadas em critérios estruturais, formais e funcionais. No entanto, ao invés de trabalhar com sequências tipológicas, defendemos a necessidade de se trabalhar com os diversos gêneros discursivos.

A professora (F7), ao justificar sua escolha por essas atividades, simplifica: "Eu gosto de fazer com que eles leiam, escrevam, que eles procurem pistas no texto, que são os elementos de coesão". Ela resume tudo na coesão. Em função da representação de aluno que habita o imaginário do professor, ele tende a simplificar os conceitos e a própria linguagem, reduzindo o que é complexo, preenchendo as faltas e tentando impedir que elas apareçam (CORACINI, 2003a).

No que tange à função que o professor de língua portuguesa exerce na formação de um cidadão consciente de seu papel na sociedade (questão seis), o discurso da professora (Aa) demonstra preocupação com o jogo de imagens (PÊCHEUX, apud CARDOSO, 2003) as quais destacamos: 1. a imagem que o professor deseja que o outro (outros professores) tenha dele como controlador do saber: "e que os outros professores tenham a humildade de chegar no professor de português. Eu não quero que vocês errem fora, mas aqui vocês podem errar, junto comigo"; 2. a imagem que o professor tem de si mesmo, pois quem fala, fala de algum lugar, a partir de um direito reconhecido institucionalmente (FOUCAULT, 2008): "Tem que deixar que o aluno tenha confiança no professor". Segundo Foucault (2006), ao analisarmos o discurso, situamos no conjunto das coisas ditas, as relações e as regularidades que podem aí ser observadas, o domínio do qual certas figuras e certos entrecruzamentos indicam o lugar singular de um sujeito falante. Assim, na primeira imagem, o professor é controlador do processo de ensino, ele fala como se as hipóteses a respeito da língua se construíssem somente no momento e no lugar em que ele tem o controle: na sala de aula. Da posição de autoridade e de poder, ela enuncia: "Sem o professor de língua portuguesa a escola não caminha", o que demonstra a imagem do professor imprescindível. 
Na segunda imagem, o professor assume a posição de amigo, pai, mãe, um ser compreensivo e sensível, imagem que a própria escola tem imprimido ao docente. Embora as imagens positivas sejam evidentes, o discurso de desvalorização emerge por um instante: "E esse professor de português não pode fazer de conta, o professor de português não pode falar amanhã eu faço", mas logo é silenciado pelo discurso anterior, mais conveniente. Há uma denúncia de que o professor não tem se comprometido realmente com o ensino, deixando algo para depois.

No que se refere à fala da professora (F7), observamos que o discurso, que até este momento de nossa pesquisa, nos remetia ao ensino tradicional, foi deslocado. $O$ sujeito até parece ser outro, ou um outro discurso faz parte das suas redes de significação: "Se o professor debate assuntos polêmicos(...) para o aluno expor as ideias dele, você está dando incentivo para aquele aluno se colocar diante das situações e dos problemas da vida lá fora".

Nesse sentido, Mussalin (2004) afirma que as sequências linguísticas possíveis de serem enunciadas por um sujeito circulam entre essa ou aquela formação discursiva que compõe o interdiscurso. A AD considera que os sujeitos são condicionados por uma determinada ideologia, que predetermina o que poderão ou não dizer em determinadas conjunturas histórico-sociais (MUSSALIN, 2004). Seu discurso é marcado por ressignificações a todo instante: "Quando eu levo um assunto polêmico, ou um assunto corriqueiro melhor ainda, algo que parece corriqueiro mas não é".

Ao falar sobre os sonhos de carreira (questão sete): "Já tive muitos. Hoje eu não tenho mais. Porque eu não vou mudar o mundo" (Aa). Segundo Huberman (1992), em professores nessa fase da carreira, o nível de ambição desce. Eles se queixam dos alunos menos disciplinados, menos motivados, de atitude negativa para com o ensino: "Me propus a ensiná-los, mas eles também não queriam"( $\mathrm{Aa}$ ). Seu discurso é atravessado por imagens negativas, que parecem separar o presente do passado, por um sentimento de nostalgia e, ao mesmo tempo, de frustração (CORACINI, 2003a):

No que se refere ao discurso da professora (F7), em relação a seu sonho "que o Estado divida a matéria de língua portuguesa com mais precisão e crie um laboratório de redação"-, é importante comparar o discurso dessa mesma professora, quando perguntada sobre as atividades de que mais gostava de desenvolver em sala de aula: "palavras cruzadas (...), redação. Eu gosto de fazer com que eles leiam, 
escrevam, que eles procurem pistas no texto, que são os elementos de coesão" (questão 7).

A professora menciona a redação (podemos compreender as habilidades de ler e escrever) e conhecimentos linguísticos como se fossem disciplinas separadas: "para que o professor de língua portuguesa não fique tão sobrecarregado, tentando passar conhecimentos linguísticos e dando redação (...), que haja um professor específico para trabalhar a redação e a interpretação de texto". Esse discurso nos leva a crer que essa professora ainda não entende o principal objetivo do ensino de língua, ampliar a competência discursiva do aprendiz. Não compreende o caráter dialógico da língua, ou seja, que o sujeito se completa e se constrói em suas falas, e não na formalidade da língua.

O discurso da professora renuncia ao "direito de concebermos, executarmos e avaliarmos - e não só executarmos - nosso trabalho educativo (...); o direito, enfim, de nos constituirmos como sujeitos/professores" (MAGNANI, 1997, p. 31). É o confronto de que Geraldi (1995) argumenta: as classes dominantes articulam os elementos, enquanto as classes dominadas, em função da apropriação dos meios de produção por aquelas, atomizam e fragmentam seus "modos de ver o mundo" (GERALDI, 1995, p. 56) e de representá-lo, sem que se Ihes permitam totalizações que levariam à reapropriação, reelaboração e projeção de seus desejos.

Enfim, é oportunizado às professoraras falarem sobre a educação no Brasil (questão oito): "Eu mesmo nasci para ser professor". Em toda nossa análise, foi notório, no discurso da professora $(\mathrm{Aa})$, as imagens positivas tradicionais, revelando uma superioridade, explicável pela convicção de que o professor seja um missionário, um ser que deva inculcar em seus alunos e na sociedade atitudes de amor, compreensão, boa vontade, ou seja, ela recebeu a missão de ser professora desde seu nascimento. Ainda que não encontre reconhecimento financeiro ou social - "O salário é ruim? É ruim sim. É um salário de fome mesmo" -, ela se realiza por estar simplesmente 'cumprindo sua missão': Reconhecemos também no discurso da professora uma possível causa do fracasso escolar: "O problema está na política (...) são eles que têm que fazer" (F7). Sobre isso, Magnani (1997) relata que posições como essas apenas têm levado a raciocínios simplistas e contribuído para que se multipliquem ações fundadas em tendências educacionais reprodutivas ou salvacionistas. 
Podemos observar outro indício no discurso, o uso de verbos na terceira pessoa, no presente atemporal, "As pessoas às vezes falam que a classe dos professores é uma classe desunida (...)" (Aa); uma marca de impessoalidade, à maneira do discurso científico (CORACINI, 2003b), ou seja, são as pessoas que dizem, não é ela quem diz. A autora alerta que "ficar de fora, olhar objetivamente ou apenas observar sem ver ou se intrometer não passa de uma grande ilusão a que estamos todos condenados enquanto participantes desse grande projeto da modernidade (...)" (2003b, p. 335).

\section{Considerações finais}

Os diferentes momentos do processo de passagem dos produtos do trabalho científico para o ensino, que moldaram a identidade do professor e constituíram e constituem a ação de ensinar, até os dias atuais, são respostas às diferentes concepções de mundo e de sujeito em cada época e aos interesses específicos de determinada formação social.

As imagens reveladas nos discursos analisados apontam para a constituição heterogênea e contraditória que forma e constrói a verdade de cada sujeito, assim como o seu discurso. Segundo Hall, "dentro de nós há identidades contraditórias, empurrando em diferentes direções, de tal modo que nossas identificações estão sendo continuamente deslocadas" (2005, p.13). Por um lado, apresentam-se como indivíduos unos e coerentes, seguros de suas concepções e práticas, realizados profissionalmente, por outro lado, abrem mão de seus sonhos e renunciam ao seu papel de sujeitos reflexivos e atuantes na sociedade.

O discurso pedagógico das professoras, sujeitos desta pesquisa, encenou profissionais ativos, responsáveis e imensamente preocupados com o ensino de língua materna. Elas demonstraram conhecimento das novas metodologias de ensino, pregando a importância do texto e da leitura, contudo, ainda não concebem a língua como forma de interação. Notamos a presença constante de vozes provenientes de um lugar menos inovador, ou seja, de concepções preconceituosas em relação à língua portuguesa, decorrentes da formação normativista a que as professoras foram submetidas. As contradições entre o saber-fazer construído ao longo de uma prática, e a inovação surgem, porém não são tão marcantes, há certa medida de "serenidade", no que diz respeito aos métodos de ensino. Serenidade essa que pode estar ligada a uma dose de comodidade, já que professores nessa fase têm tendência a aceitar a 
ideia de que as modificações raramente conduzem a melhorias no sistema (HUBERMAN, 1992).

O discurso das professoras, em final de carreira, quase sempre é pautado na autoridade, fruto das imagens positivas tradicionais, advindas da autoridade do saber científico, como forma até mesmo de autenticar sua autoridade institucional. Como detentoras e controladoras do saber, identificam a missão do professor como a transmissão de um legado divino, o que também deixa implícita a autoridade de quem recebe essa missão. Porém, em todo momento, notamos um sujeito disperso, heterogêneo e inconsciente da heterogeneidade de seu discurso.

As professoras não apresentaram sequer a consciência de que a escola é um Aparelho Ideológico do Estado; instituição encarregada de inculcar a ideologia dominante pelo conhecimento e valores culturais que transmite e pela imposição arbitrária da ação pedagógica, cujo realizador é o professor. Essa consciência conduziria o educador a uma visão desalienante, pronto para acolher as inovações, sujeito de sua própria história, tecendo-a como a um pano de múltiplos e variados fios, que se entrelaçam, que se confundem, que se dividem e que se multiplicam em sentidos vários, reconstituindo, enfim, o seu fazer, assim como seu discurso.

\section{Referências bibliográficas}

BAKHTIN, M. Marxismo e Filosofia da linguagem. Rio de Janeiro: Hucitec, 2004. BRASIL. Parâmetros Curriculares Nacionais de Língua Portuguesa - Terceiro e Quarto Ciclos. Brasília: MEC/SEF, 1998. Disponível em:

<http://portal.mec.gov.br/seb/arquivos/pdf/ttransversais.pdf>. Acesso em: 10 maio 2010.

CARDOSO, S. H. B. Discurso e ensino. $2^{2}$ ed. Belo Horizonte: Editora Autêntica, 2005.

CORACINI, M. J. R. F. A teoria e a prática: a questão da diferença no discurso sobre e da sala de aula. Delta, v. 14, n. 1, p. 33-57, 1998. Disponível em: <htttp://www.scielo.br/scielo.php>. Acesso em: 28 set. 2006.

. A celebração do outro. In: (Org.). Identidade e discurso: (des)construindo subjetividades. Campinas; Chapecó: Editora da Unicamp; Argos Editora Universitária, 2003a. p. 197-221

. As representações do saber científico na constituição da identidade do sujeito-professor e do discurso de sala de aula. In: (Org.). Identidade e

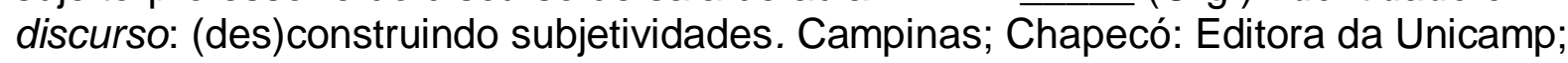
Argos Editora Universitária, 2003b. p. 319-336. 
ECKERT-HOFF, B. A denegação como possibilidade de "captura" do não um no tecido do dizer In: CORACINI, Maria José Rodrigues Faria (Org.). Identidade e discurso: (des)construindo subjetividades. Campinas; Chapecó: Editora da Unicamp; Argos Editora Universitária, 2003. p. 285-302.

FOUCAULT, M. A ordem do discurso. 14ª̣ed. São Paulo: Loyola, 2006. A arqueologia do saber. $7^{\mathrm{a}} \mathrm{ed}$. Rio de Janeiro: Forense Universitária, 2008.

GAUTHIER, C. Ensinar: ofício estável, identidade profissional vacilante. In: SILVA, M. (Org). Pedagogia cidadã: cadernos de formação: caderno de didática. São Paulo: UNESP; Pró-reitoria de Graduação, 2003.

GERALDI, J. W. Portos de passagem. $3^{\text {a}}$ ed. São Paulo: Editora Martins Fontes, 1995.

GOLDENBERG, M. A arte de pesquisar. 8ªed. São Paulo: Record, 2004.

HALL, S. A identidade cultural na pós-modernidade. $10^{\circledR}$ ed. Rio de Janeiro: DP\&A, 2005.

HUBERMAN, M. O ciclo de vida profissional dos professores. In: NÓVOA, A. (Org.). Vidas de professores. Lisboa: Porto Editora, 1992. p. 31-61.

MAGNANI, M. R. M. Em sobressaltos. 2ª ed. Campinas: Editora da Unicamp, 1997.

MARTINS, S. A. F. O professor iniciante: seu trabalho com o texto na sala de aula. 2002. Tese (Doutorado em Letras) - Faculdade de Ciências e Letras, Universidade do Estado de São Paulo, Assis-SP, 2002.

MUSSALIN, F. Análise do discurso in: MUSSALIN, Fernanda; BENTES, Anna Christina (Orgs.). Introdução à linguística: domínios e fronteiras. 4ª̣ed, São Paulo: Cortez, 2004, v 2. p. 101-142.

ORLANDI, E. P. A linguagem e seu funcionamento. São Paulo: Editora Brasiliense, 1983. 1999 .

Análise de discurso: princípios e procedimentos. Campinas-SP: Pontes,

ROJO, R. (Org.). A prática de linguagem em sala de aula: praticando os PCNs.

Campinas- SP: EDUC, 2000.

SAUSSURE, F. Curso de linguística geral. 20ํㅡㄹ ed. São Paulo: Editora Cultrix, 1995. SAVIANI, D. O legado educacional do século XX no Brasil. Campinas-SP: Autores Associados, 2006. 